\title{
Theoretical studies on energetic materials bearing pentaflurosulphyl (SF 5$)$ groups
}

\author{
LI XIAO-HONG ${ }^{\mathrm{a}, \mathrm{b}, *}$, CUI HONG-LING ${ }^{\mathrm{a}}, \mathrm{JU}^{\text {WEI-WEI }}{ }^{\mathrm{a}}$, LI TONG-WEI $^{\mathrm{a}}$, \\ ZHANG RUI-ZHOU, ${ }^{\mathrm{a}, \mathrm{b}}$ and YONG YONG-LIANG ${ }^{\mathrm{a}}$ \\ ${ }^{a}$ College of Physics and Engineering, Henan University of Science and Technology, Luoyang 471003, China \\ ${ }^{b}$ Luoyang Key Laboratory of Photoelectric Functional Materials, Henan University of Science \\ and Technology, Luoyang 471023, China \\ e-mail: lorna639@126.com
}

MS received 3 October 2013; revised 7 January 2014; accepted 3 March 2014

\begin{abstract}
Heats of formation (HOF) for a series of energetic materials containing $\mathrm{SF}_{5}$ group were studied by density functional theory. Results show that HOFs increase with the augmention of field effects of substituted groups. Addition of furazan or furoxan ring increases $\mathrm{HOF}$ of the energetic materials. All the $\mathrm{SF}_{5}$-containing compounds have densities which are $\sim 0.19 \mathrm{~g} / \mathrm{cm}^{3}$ higher than those containing $-\mathrm{NH}_{2}$ group. $\mathrm{S}-\mathrm{F}$ bond is the trigger bond for the thermolysis process in the title compounds and bond dissociation energies of the weakest bonds range from 351.1 to $388.3 \mathrm{~kJ} / \mathrm{mol}$. Detonation velocities (D) and pressures (P) are evaluated by KamletJacobs equations with the calculated densities and HOFs. Results show that increasing the amount of furazan rings results in a larger $\mathrm{D}$ and $\mathrm{P}$. Considering the detonation performance and thermal stability, eight compounds may be considered as potential candidates for high-energy density materials.
\end{abstract}

Keywords. Density functional theory; pentafluorosulphanyl groups; heats of formation; detonation properties; density.

\section{Introduction}

Design of new energetic materials with improved performance and decreased sensitivity is one of the main goals of chemists. ${ }^{1,2}$ Synthesis of new high energy materials has been focused on the use of heterocyclic compounds with high nitrogen content such as furazan or furoxan due to the positive heats of formation (HOF), high density and high thermal stability of these compounds. ${ }^{3-6}$ Chemistry of furazan and furoxan is of great interest. ${ }^{7}$ Furazan-based derivatives are interesting candidates for high energy density materials (HEDMs), because furazan ring $\left(\mathrm{C}_{2} \mathrm{H}_{2} \mathrm{ON}_{2}\right.$, an energetic high-nitrogen heterocyclic group) has high formation enthalpy, fine thermal stability and active-oxygenbearing cycle..$^{8,9}$

Generally, new energetic materials are compared to two of the most important known energetic materials: hexahydro-1,3,5-trinitro-1,3,5-triazine (RDX) and 1,3,5,7-tetranitro-1,3,5,7- tetraazacyclooctane (HMX) to evaluate their detonation performance. Fluorine is often incorporated into the energetic materials in order to achieve better performance than RDX and HMX. ${ }^{10,11}$

*For correspondence
During recent decades, introduction of the $\mathrm{SF}_{5}$ group into the energetic compounds has further improved their performance, mainly due to the increase in their density, larger energy release, and better thermal and chemical stability without increasing the sensitivity. ${ }^{12,13}$ High fluorine content along with the presence of hydrogen leads to the formation of hydrogen fluoride upon detonation, generating a large amount of energy.

Generally, introduction of nitro groups provides a better oxygen balance for furazan ring, but displays poor thermal and chemical stability for tetrazine. Introduction of an amino group can improve thermal stability of the explosive. If the $\mathrm{SF}_{5}$ group is incorporated to the furazan ring or other energetic materials, what changes will the properties of the new energetic materials produce?

Properties are often manipulated by making structural modifications, so predicting the properties and performance is necessary for the new candidates of HEDM before the dangerous and expensive synthesis. Therefore, optimizing the designed HEDMs with high density and energy is the first step to search and synthesize HEDMs.

Introduction of fluorine into energetic compounds has resulted in a boost in their performance, so a series of furazan-containing energetic materials with 
$\mathrm{SF}_{5}$ group are investigated (see figure 1 for structural diagrams of these compounds) in order to find new energetic materials in this study. Their heats of formation, densities, and explosive performances were investigated using density functional theory (DFT) method. It is expected that our results could provide useful information for laboratory synthesis and design and development of new novel energetic materials.<smiles>[CH]OC(=O)C(P)(P)S(F)(F)(F)(F)F</smiles>

(1)<smiles>O=C(O)C(F)(P)S(F)(F)(F)(F)F</smiles>

(2)

(6)<smiles>O=C(CS(F)(F)(F)(F)F)Nc1nnn[nH]1</smiles>

(9)

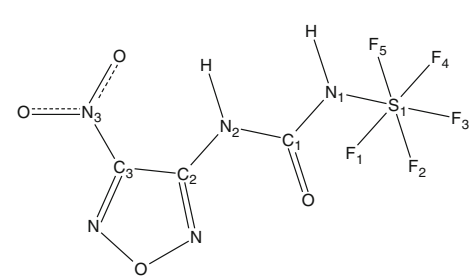

(12)
(5)<smiles>O=C(CS(F)(F)(F)(F)F)Nc1nonc1-c1nnn[nH]1</smiles>

(8)<smiles>CN(NC(=O)Nc1nonc1N)S(F)(F)(F)(F)F</smiles>

(11)

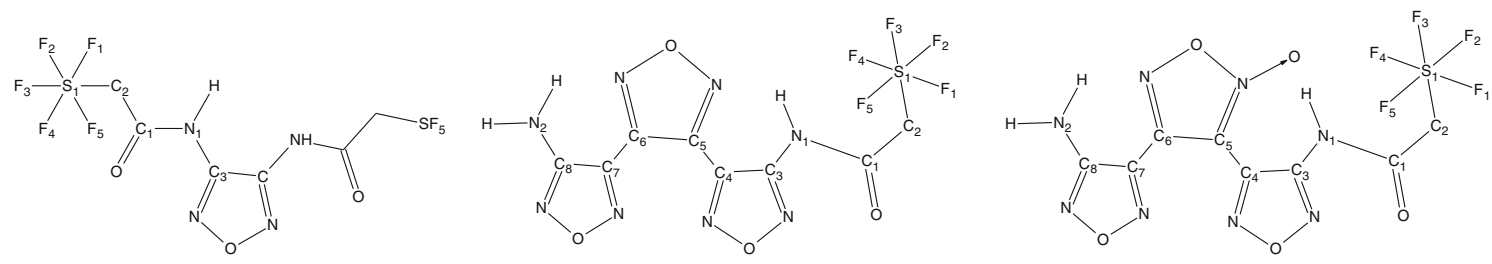<smiles>Nc1nonc1NC(=O)CS(F)(F)(F)(F)F</smiles>

(4)
(3)<smiles></smiles>

(7)

Figure 1. Molecular frameworks of energetic material containing $\mathrm{SF}_{5}$ group. 


\section{Experimental}

Geometry optimization of molecular structures were performed without any symmetry restriction by using DFT at the B3LYP level with the $6-31 \mathrm{G}^{* *}$ basis set in Gaussian 03 package. ${ }^{14}$ Vibrational frequency analyses were performed at the same level. All optimized structures were characterized to be the local energy minimum on the potential energy surface by vibrational analysis. This indicates that the structure of each molecule corresponds to a local minimum on the potential energy surface. The $\left\langle S^{2}\right\rangle$ values are all very close to 0.75 , which shows negligible spin contamination of pure doublet states for fragment open-shell systems.

Previous studies show that DFT-B3LYP method is successfully used to predict the HOFs of many organic systems via isodesmic reactions. ${ }^{15,16}$ The computational details of isodesmic reaction processes are given in previous studies. ${ }^{17}$

For each title compound, explosive reaction is designed in terms of the maximal exothermal principle. All the $\mathrm{N}$ atoms turn into $\mathrm{N}_{2}$, the $\mathrm{O}$ atoms react with the $\mathrm{H}$ atoms to give $\mathrm{H}_{2} \mathrm{O}$ at first, and then form $\mathrm{CO}_{2}$ with the $\mathrm{C}$ atom and form $\mathrm{SO}_{2}$ with $\mathrm{S}$ atom. If the number of $\mathrm{O}$ atoms is more than what is needed to oxidize $\mathrm{H}, \mathrm{C}$ and $\mathrm{S}$ atoms, redundant $\mathrm{O}$ atoms will convert into $\mathrm{O}_{2}$. If the content of $\mathrm{O}$ is not enough to satisfy complete oxidation of the $\mathrm{H}, \mathrm{C}$ and $\mathrm{S}$ atoms, the remaining $\mathrm{H}$ atoms will convert into $\mathrm{H}_{2}, \mathrm{C}$ atoms will exist as solid-state $\mathrm{C}$ and $\mathrm{S}$ atoms exist as solid-state S. Halogen atoms form hydrogen halide with hydrogen atoms.

Important factors to scale the detonation characteristics of energetic materials are detonation velocity $(D)$ and detonation pressure $(P)$, which are directly related to the density of the compound according to KamletJacobs (K-J) equations. ${ }^{18,19}$ Density is one of the most important factors that determine the detonation properties of energetic compounds. According to the $\mathrm{K}-\mathrm{J}$ equations, ${ }^{18,19} \mathrm{P}$ is dependent on the square of the density, while $D$ is proportional to the density, so density is a key parameter to calculate the detonation properties. In addition, HOF is also a key parameter for effective energetic materials.

For a series of explosives with $\mathrm{C}, \mathrm{H}, \mathrm{N}, \mathrm{O}, \mathrm{F}, \mathrm{Cl}$, and $\mathrm{S}$ elements, detonation velocities and pressures can be calculated by using $\mathrm{K}-\mathrm{J}$ equations: ${ }^{18,19}$

$$
\begin{gathered}
D=1.01 \times \Phi^{0.5}(1.0+1.3 \rho), \\
\Phi=N \bar{M}^{0.5} Q^{0.5}, \\
P=1.558 \times \Phi \rho^{2},
\end{gathered}
$$

where each term in eqs. (1) and (3) is defined as follows: $P$, detonation pressure $(\mathrm{GPa}) ; D$, the detonation velocity $(\mathrm{km} / \mathrm{s}) ; \rho$, the density of the explosive $\left(\mathrm{g} / \mathrm{cm}^{3}\right)$; $\Phi$, the characteristics value of explosives; $N$, the moles of gas produced by per gram of explosives; $\bar{M}$, an average molar weight of detonation products; and $Q$, the estimated heat of detonation (cal/g). Crystal density can be calculated by electrostatic potential on the molecular surfaces:

$$
\rho=\alpha\left(\frac{M}{V(0.001)}\right)+\beta\left(v \sigma_{\text {tot }}^{2}\right)+\gamma .
$$

In eq. (4), $M$ is the molecular mass in $\mathrm{g} /$ molecule, $V(0.001)$ is the volume of the isolated gas phase molecule, in $\mathrm{cm}^{3} /$ molecule. Coefficients $\alpha, \beta$ and $\gamma$ were obtained by Politer et al. ${ }^{20}$

For the $\mathrm{C}_{a} \mathrm{H}_{b} \mathrm{O}_{c} \mathrm{~N}_{d} \mathrm{~F}_{e} \mathrm{Cl}_{f} \mathrm{~S}_{g}$ explosives studied here, $2 a+b / 2+2 g>c, \mathrm{~N}, \bar{M}$ and Q are calculated according to the following formula:

$$
\begin{gathered}
N=(2 a+b+d+e+f+2 g) / 2 M, \\
\bar{M}=\frac{39.3 a+1.2 b+2.35 c+14 d+18.8 e+35.3 f+66.31 g}{2 a+b+d+e+f+2 g} \times 2, \\
Q \times 10^{3}=\frac{43.18 a+5.44 b+68.6 c-70.82 e-41.16 f+66.31 g+0.239 \Delta H_{f}^{o}}{M},
\end{gathered}
$$

where $a, b, c, d, e, f$ and $g$ stand for the number of $\mathrm{C}, \mathrm{H}, \mathrm{O}, \mathrm{N}, \mathrm{F}, \mathrm{Cl}, \mathrm{S}$ atoms in the compound, respectively.

Whether the energetic materials are kinetically stable enough is another important concern. Thus, it is important and essential to study the bond dissociation or pyrolysis mechanism, which is directly related to the stability of the energetic compounds. A good candidate for HEDM should have a high stability, so it is important to study the bond dissociation or pyrolysis mechanism in order to understand the decomposition process of the energetic materials. The gas-phase bond dissociation energy (BDE) for a bond $\mathrm{R}_{1}-\mathrm{R}_{2}$ can be calculated from the homolytic dissociation equations: ${ }^{21}$

$$
\begin{aligned}
R_{1}-R_{2}(g) \rightarrow & R_{1} \cdot(g)+R_{2} \cdot(g), \\
B D E\left(R_{1}-R_{2}\right)= & H_{298}\left(R_{1 .} \cdot\right)+H_{298}\left(R_{2 .} \cdot\right) \\
& -H_{298}\left(R_{1 .}-R_{2}\right),
\end{aligned}
$$

where $\mathrm{R}_{1}-\mathrm{R}_{2}$ denotes the neutral molecules, and $R_{1}$. and $R_{2}$. stand for the corresponding product radicals after the bond dissociation. 


\section{Results and Discussion}

\subsection{Heats of formation}

Atomization reaction or isodesmic reaction method can be used to obtain the standard gas-phase HOFs at $298.15 \mathrm{~K}$. In this study isodesmic reaction method is used. ${ }^{22}$ The HOF obtained theoretically is conditioned by HOFs of the reference compounds. Table 1 lists the total energies, experimental HOFs and zeropoint energies at $\mathrm{B} 3 \mathrm{LYP} / 6-31 \mathrm{G}^{* *}$ method for reference compounds involved in the isodesmic reactions.

In the isodesmic reaction, experimental HOFs of many reference compounds are available, while others are unavailable. For example, experimental HOF of furazan is not available. So, addition calculations were carried out for the atomization reaction $\mathrm{C}_{2} \mathrm{H}_{2} \mathrm{ON}_{2}(\mathrm{~g})=$ $2 \mathrm{C}(\mathrm{g})+2 \mathrm{H}(\mathrm{g})+\mathrm{O}(\mathrm{g})+2 \mathrm{~N}(\mathrm{~g})$ to get an accurate value $\Delta H_{\mathrm{f}}$ value for furazan. Recent studies ${ }^{29}$ show that the G2 model presents the most accurate HOFs among the high-level models, such as G3, CBS-4M, CBS-Q, CBSQB2, G2(MP2). So in our study, G2 $2^{30}$ theory was used to calculate $\mathrm{HOF}$ value of furazan, furoxan, $\mathrm{CH}_{3} \mathrm{SF}_{5}$ and $\mathrm{C}\left(\mathrm{NO}_{2}\right)_{2}\left(\mathrm{CH}_{3}\right)_{2}$.

Table 2 presents the total energies, ZPEs, $\Delta H_{\mathrm{f} \text {,gas }}$ of the title energetic materials. It is noted that the
HOFs of the studied furazan-based energetic materials have negative HOFs due to the presence of the pentafluorosulphanyl $\left(\mathrm{SF}_{5}\right)$ group.

Compound (10) is considered as a baseline material. It has been previously synthesized ${ }^{33}$ and exhibited good thermal stability. When compared with compound (1), all our energetic materials exhibited bigger HOFs. Compounds (1), (2) and (3) are three energetic materials containing $\mathrm{SF}_{5}$ group but without furazan ring. Field effects (electrostatic effect of a charge or dipole transmitted through space) of $\mathrm{OCH}_{3}, \mathrm{OH}, \mathrm{Cl}$ groups are 0.25 , 0.30 and 0.45 respectively. ${ }^{34}$ Their HOFs are -1559.3 , -1539.8 and $-1363.6 \mathrm{~kJ} / \mathrm{mol}$, respectively. Obviously, the HOFs increase with the augmention of field effects of substituted groups.

Compounds (4), (5), (11), (12) and (13) are energetic compounds containing one furazan ring. The $\mathrm{HOF}$ of compound (4) is $-1164.3 \mathrm{~kJ} / \mathrm{mol}$. The HOF drastically decreases when the $-\mathrm{NH}_{2}$ group of compound (4) is substituted by $-\mathrm{NHCOCH}_{2} \mathrm{SF}_{5}$ group. Comparing the HOFs of compounds (4) and (5), we can see that the more the $-\mathrm{NHCOCH}_{2} \mathrm{SF}_{5}$ group is, the more negative the $\mathrm{HOF}$ is. In addition, the HOF slightly decreases when the $-\mathrm{NHCOCH}_{2} \mathrm{SF}_{5}$ group of compounds (4) is substituted by $-\mathrm{NHCONHSF}_{5}$ group. Similar conclusion can be made for compounds (12) and (13).

Table 1. Calculated total energy $\left(E_{0}\right)$, zero-point energy (ZPE) and experimental heats of formation (HOF) of the reference compounds at B3LYP/6-31G** method. $E_{0}$ and ZPE are in a.u., HOFs are in kJ/mol.

\begin{tabular}{lccr}
\hline Compound & $E_{0}$ & ZPE & HOF \\
\hline $\mathrm{CH}_{4}$ & -40.478949 & 0.045065 & $-74.8^{\mathrm{a}}$ \\
$\mathrm{C}_{2} \mathrm{H}_{6}$ & -79.763803 & 0.074936 & $-84.0^{\mathrm{a}}$ \\
$\mathrm{CH}_{3} \mathrm{NO}_{2}$ & -244.963419 & 0.049955 & $-80.7^{\mathrm{a}}$ \\
$\mathrm{CH}_{3} \mathrm{COOCH}$ & -268.306850 & 0.089913 & $-410.1^{\mathrm{b}}$ \\
$\mathrm{CH}_{3} \mathrm{COCl}$ & -613.402751 & 0.047418 & $-242.4^{\mathrm{b}}$ \\
$\mathrm{CH}_{3} \mathrm{CONHCH}$ & -248.429071 & 0.10217 & $-247.7^{\mathrm{b}}$ \\
$\mathrm{NH}_{3}$ & -56.523331 & 0.034437 & $-45.9^{\mathrm{b}}$ \\
$\mathrm{CH}_{3} \mathrm{NHCONH}_{2}$ & -264.490035 & 0.091982 & $-235.7^{\mathrm{b}}$ \\
$\mathrm{CH}_{3} \mathrm{NH}_{2}$ & -95.799472 & 0.064214 & $-22.6^{\mathrm{c}}$ \\
$\mathrm{CH}_{3} \mathrm{COOH}$ & -229.029523 & 0.061957 & $-432.2^{\mathrm{d}}$ \\
$\mathrm{Furazan}^{\text {Furoxan }}$ & -262.004376 & 0.045835 & $196.2^{\mathrm{e}}$ \\
$\left.\mathrm{C}_{2} \mathrm{NO}_{2}\right)_{2}\left(\mathrm{CH}_{3}\right)_{2}$ & -337.159576 & 0.049696 & $197.8^{\mathrm{e}}$ \\
$\mathrm{CH}_{3} \mathrm{SF}_{5}$ & -528.030353 & 0.108876 & $-141.5^{\mathrm{e}}$ \\
$\mathrm{NH}_{2} \mathrm{SF}_{5}$ & -937.142879 & 0.055352 & $-1225.1^{\mathrm{e}}$ \\
$\mathrm{NH}_{2} \mathrm{COOCH}$ & -953.181792 & 0.044593 & $-1302.9^{\mathrm{e}}$ \\
$1 \mathrm{H}-$ tetrazole & -284.368666 & 0.079521 & $-425.3^{\mathrm{f}}$ \\
\hline
\end{tabular}

${ }^{\text {a Data Ref. }}{ }^{23}$

${ }^{b}$ Data Ref. ${ }^{24}$

${ }^{\mathrm{c}}$ Data Ref. ${ }^{25}$

${ }^{\mathrm{d}}$ Data Ref. ${ }^{26}$

'The value are calculated at the $\mathrm{G} 2$ level from the atomization reaction

${ }^{\mathrm{f}}$ Data Ref. ${ }^{27}$

${ }^{\mathrm{g}}$ Data Ref. ${ }^{28}$. 
Table 2. Calculated total energies $\left(E_{0}\right)$, zero-point energies (ZPE), densities and heats of formation (HOFs) for the title energetic materials. $E_{0}$ and $\mathrm{ZPE}$ are in a.u., HOFs are in $\mathrm{kJ} / \mathrm{mol}$, densities are in $\mathrm{g} / \mathrm{cm}^{3}$.

\begin{tabular}{lcccccc}
\hline Compound & $E_{0}$ & $\mathrm{ZPE}$ & $\Delta H_{\mathrm{f}, \text { gas }}$ & $\Delta H_{\mathrm{f}, \text { sub }}$ & $\Delta H_{\mathrm{f}, \text { solid }}$ & Density \\
\hline $\mathbf{1}$ & -1164.9630 & 0.0985 & -1559.3 & 78.6 & -1637.9 & 2.05 \\
$\mathbf{2}$ & -1125.6846 & 0.0705 & -1539.8 & 76.4 & -1616.2 & 2.23 \\
$\mathbf{3}$ & -1510.0556 & 0.0560 & -1363.6 & 68.3 & -1431.9 & 2.19 \\
$\mathbf{4}$ & -1421.9731 & 0.1263 & -1164.3 & 104.9 & -1269.2 & 2.04 \\
$\mathbf{5}$ & -2471.2464 & 0.1725 & -2486.6 & 151.0 & -2637.6 & 2.21 \\
$\mathbf{6}$ & -1943.6331 & 0.1792 & -744.0 & 158.2 & -902.2 & 1.96 \\
$\mathbf{7}$ & -2018.7831 & 0.1834 & -728.7 & 162.0 & -890.7 & 1.91 \\
$\mathbf{8}$ & -1623.6659 & 0.1368 & -826.7 & 127.8 & -954.5 & 2.03 \\
$\mathbf{9}$ & -1362.8321 & 0.1104 & -1027.0 & 102.9 & -1129.9 & 2.09 \\
$\mathbf{1 0}$ & -2809.0599 & 0.1888 & -3181.1 & 189.1 & -3370.2 & 2.25 \\
$\mathbf{1 1}$ & -1438.0101 & 0.1144 & -1210.3 & 107.6 & -1317.9 & 2.10 \\
$\mathbf{1 2}$ & -1587.1446 & 0.1007 & -1191.3 & 101.9 & -1293.2 & 2.20 \\
$\mathbf{1 3}$ & -1571.0524 & 0.1113 & -1122.9 & 105.4 & -1228.4 & 2.12 \\
HMX $^{\mathrm{a}}$ & -1196.3655 & 0.0459 & $175.4(192)$ & 91.2 & 84.2 & $1.89(1.90)$ \\
RDX $^{\mathrm{a}}$ & -897.2732 & 0.0342 & $210.4(250)$ & 118.4 & 92.0 & $1.78(1.82)$ \\
\hline
\end{tabular}

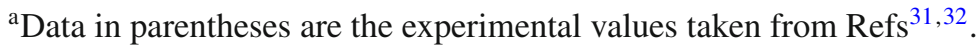

Inspecting table 2, it is noted that the HOFs of compounds (6) and (7) are much bigger than those of the other studied compounds. This is a good indication that the addition of furazan or furoxan ring increases HOF of the energetic materials. This conclusion can also be proved by the comparison of compounds (8) and (9). The HOFs of compounds (6) and (7) are -744.0 and $-728.7 \mathrm{~kJ} / \mathrm{mol}$, respectively. This shows that substitution of furoxan group in compound (6) slightly increases the HOF. Comparing the structures of compounds (4), (5) and (8), substitution of tetrazole ring in compound (4) drastically increases the HOF.

Since, the condensed phase for most energetic compounds is solid, calculation of detonation properties requires solid phase $\mathrm{HOF}\left(\Delta H_{\mathrm{f} \text {, solid }}\right)$. According to Hess's law of constant heat summation, ${ }^{35}$ the gas-phase $\operatorname{HOF}\left(\Delta H_{\mathrm{f}, \text { gas }}\right)$ and heat of sublimation $\left(\Delta H_{\mathrm{f}, \text { sub }}\right)$ can be used to evaluate their solid phase HOF.

$$
\Delta H_{\mathrm{f}, \text { solid }}=\Delta H_{\mathrm{f}, \text { gas }}-\Delta H_{\mathrm{f}, \text { sub }} .
$$

Politzer et al. found that the heats of sublimation can correlate well with the molecular surface area and electrostatic interaction index $\nu \delta_{\text {tot }}^{2}$ of energetic compounds. ${ }^{36,37}$ Empirical expression of the approach is as follows:

$$
\Delta H_{\text {sub }}=a A^{2}+b \sqrt{v \delta_{\mathrm{tot}}^{2}}+c,
$$

where $A$ is the surface area of the 0.001 electrons $/$ bohr $^{3}$ isosurface of electronic density of the molecule, $v$ describes the degree of balance between positive and negative potential on the isosurface and $\delta_{\text {tot }}^{2}$ is a measure of variability of the electrostatic potential on the molecular surface. Coefficients $a, b$ and $c$ were determined by Rice \& coworker. ${ }^{22}$ The descriptors A, $v$ and $\delta_{\text {tot }}^{2}$ were calculated using computational procedures proposed by $\mathrm{Lu}^{38}$

Crystal densities, $\Delta H_{\mathrm{f} \text {, sub }}$ and $\Delta H_{\mathrm{f} \text {, solid }}$ of the title compounds are also included in table 2. For comparisons, experimental densities and HOF of HMX and RDX are also listed in this table. It is noted that densities of the studied compounds range between 1.91 and $2.25 \mathrm{~g} / \mathrm{cm}^{3}$, which are all bigger than those of RDX and HMX.

In order to explain the performance of $\mathrm{SF}_{5}$ group, densities of some other compounds are also computed and these compounds are listed in figure 2. Their densities are listed in table 3. Densities of compounds (6), (7), (8) and (9) are also included in order to have a comparison.

With the substitution of one $\mathrm{SF}_{5}$ group, $\mathrm{HOF}$ of compounds (6), (7), (8) and (9) are all larger than those of compounds (14), (15), (16) and (17), respectively. This indicates that the presence of $\mathrm{SF}_{5}$ functional group greatly enhances the density of these compounds. All the $\mathrm{SF}_{5}$-containing compounds have densities which are $\sim 0.19 \mathrm{~g} / \mathrm{cm}^{3}$ higher than those containing- $\mathrm{NH}_{2}$ group.

\subsection{Detonation properties}

To find a new energetic material, it is essential to evaluate $D$ and $P$ by using the $\mathrm{K}-\mathrm{J}$ equations. ${ }^{17,18}$ Based on the HOFs and densities of the title compounds, the detonation properties, including $Q, D$ and $P$, were estimated. Table 4 lists the calculated HOF, $V, D, P, Q$ and the 


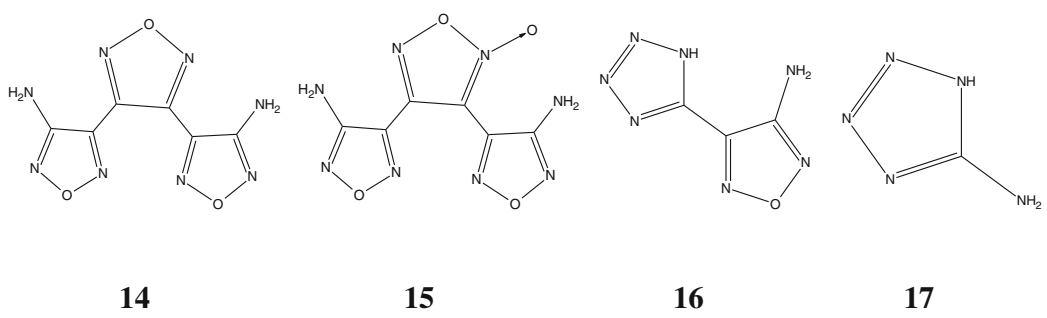

Figure 2. Molecular frameworks of the other energetic materials.

Table 3. Calculated densities $\left(\mathrm{g} / \mathrm{cm}^{3}\right)$ for the other energetic materials containing $\mathrm{SF}_{5}$ group.

\begin{tabular}{lccc}
\hline Compound & Density & Compound & Density \\
\hline $\mathbf{6}$ & 1.96 & 14 & 1.71 \\
$\mathbf{7}$ & 1.91 & 15 & 1.70 \\
$\mathbf{8}$ & 2.03 & 16 & 1.67 \\
$\mathbf{9}$ & 2.09 & 17 & 1.55 \\
\hline
\end{tabular}

oxygen balances $\left(\mathrm{OB}_{100}\right)$ of the title compounds. The $\mathrm{OB}_{100}$ is calculated using the following formula.

$$
O B_{100}=\frac{n_{\mathrm{O}}-\left(0.5 * n_{\mathrm{H}}+2 n_{\mathrm{C}}+2 n_{\mathrm{S}}\right)}{M} \times 16 \times 100,
$$

where $n_{\mathrm{O}}, n_{\mathrm{H}, n_{\mathrm{C}}}$ and $n_{\mathrm{S}}$ represent the numbers of $\mathrm{O}, \mathrm{H}$, $\mathrm{C}$ and $\mathrm{S}$ atoms, respectively; $M$ is the molecular weight.

For better comparing and evaluating detonation performance of the title compounds, the experimental data $^{39}$ of RDX and HMX are also listed in table 4. The HOFs of HMX and RDX are obtained through the isodesmic reaction: $\mathrm{X}-\left(\mathrm{NO}_{2}\right)_{n}+n \mathrm{CH}_{4} \rightarrow \mathrm{X}-\mathrm{H}+$ $n \mathrm{CH}_{3} \mathrm{NO}_{2}(4 \leq n \leq 8)$, where the HOF of $\mathrm{X}-\mathrm{H}$ molecule is carried out for the atomization reaction by $\mathrm{G} 2$ theory. As is evident from table 4, the calculated detonation properties of RDX and HMX agree well with the available experimental values. ${ }^{39}$ Although, errors caused by limitations of the calculation method make the predicted properties deviate somewhat from the experimental values, these computational results are still reliable.

From table 4 , it is observed that $D$ and $P$ of furazancontaining energetic materials are all larger than those of compounds (1), (2), (3) and (10). This indicates that the introduction of furazan ring increases the detonation properties.

The $D$ and $P$ of compound (4) are $9.54 \mathrm{GPa}$ and $43.37 \mathrm{~km} / \mathrm{s}$, respectively. The $\mathrm{D}$ and $\mathrm{P}$ values decrease when the $-\mathrm{NHCOCH}_{2} \mathrm{SF}_{5}$ group of compound (4) is substituted by $-\mathrm{NHCONHSF}_{5}$ group. Similar conclusion can also be made for compounds (12) and (13). Inspecting figure 1 and table 4, compounds (6) and (7) all have two or three furazan rings, and their detonation properties are much bigger than those of the other studied compounds. This indicates that the more the

Table 4. Predicted detonation properties of the title compounds ${ }^{\mathrm{a}}$.

\begin{tabular}{lccccc}
\hline Compound & $\mathrm{OB}_{100}$ & $\mathrm{~V}$ & $\mathrm{Q}$ & $\mathrm{D}$ & $\mathrm{P}$ \\
\hline $\mathbf{1}$ & -68.0 & 94.69 & 377.4 & 8.24 & 32.43 \\
$\mathbf{2}$ & -47.3 & 81.68 & 189.4 & 6.91 & 23.85 \\
$\mathbf{3}$ & -46.8 & 89.76 & 212.7 & 6.89 & 23.49 \\
$\mathbf{4}$ & -62.7 & 130.67 & 697.1 & 9.54 & 43.37 \\
$\mathbf{5}$ & -58.7 & 192.68 & 512.7 & 9.19 & 50.79 \\
$\mathbf{6}$ & -65.3 & 202.34 & 1084.6 & 10.44 & 50.39 \\
$\mathbf{7}$ & -61.4 & 206.76 & 1179.3 & 10.47 & 47.12 \\
$\mathbf{8}$ & -59.8 & 157.44 & 853.9 & 9.96 & 41.00 \\
$\mathbf{9}$ & -56.9 & 121.08 & 594.3 & 9.21 & 31.67 \\
$\mathbf{1 0}$ & -28.6 & 222.14 & 402.0 & 7.94 & 36.67 \\
$\mathbf{1 1}$ & -47.6 & 128.38 & 523.7 & 8.70 & 43.69 \\
$\mathbf{1 2}$ & -26.8 & 131.53 & 653.8 & 8.83 & $35.13(34.00)$ \\
$\mathbf{1 3}$ & -40.3 & 136.31 & 823.1 & 9.50 & $38.24(39.00)$ \\
RDX $^{\mathrm{b}}$ & -21.6 & - & 6500 & $8.98(8.75)$ & $9.35(9.10)$ \\
HMX $^{\mathrm{b}}$ & -21.6 & - & 6700 & & \\
\hline
\end{tabular}

${ }^{\mathrm{a}}$ Units: $\mathrm{V} /\left(\mathrm{cm}^{3} \mathrm{~mol}^{-1}\right), \mathrm{Q} /\left(\mathrm{J} \mathrm{g}^{-1}\right), \mathrm{D} /\left(\mathrm{km} \mathrm{s}^{-1}\right), \mathrm{P} /(\mathrm{GPa})$

${ }^{\mathrm{b}}$ Data for RDX and HMX are taken from Ref. ${ }^{39}$. 
number of furazan ring, the larger the $D$ and $P$. Comparison of compounds (8) and (9) can also prove the conclusion. In addition, substitution of tetrazole ring drastically increases the detonation properties through comparing the structures of compounds (4), (5) and (8).

Figure 3 presents the detonation properties of the title compounds together with commonly used explosives RDX and HMX. From figure 3, we can see that densities of the title compounds are all larger than $1.90 \mathrm{~g} / \mathrm{cm}^{3}$, which are larger than those of RDX and HMX. The $D$ values of compounds (4), (6)-(8) and (13) are larger than that of HMX, $D$ values of compounds (5) and (9) are larger than that of RDX and lower than that of HMX. The $P$ values of compounds (1)-(3) and (10) are lower than that of RDX, $P$ value of compound (11) is larger than that of RDX and lower than that of HMX and $P$ values of the other eight compounds are all larger than that of HMX. As suggested, according to the criteria for a high density material, i.e., $D \approx 9 \mathrm{~km} / \mathrm{s}$ and $P \approx 40 \mathrm{GPa}$, it may be concluded that compounds (4)-(9), and (13) have good detonation performances $(D$ and $P)$.

\subsection{Electronic structure and thermal stability}

Whether the energetic materials are kinetically stable enough is another important concern. Strength of the
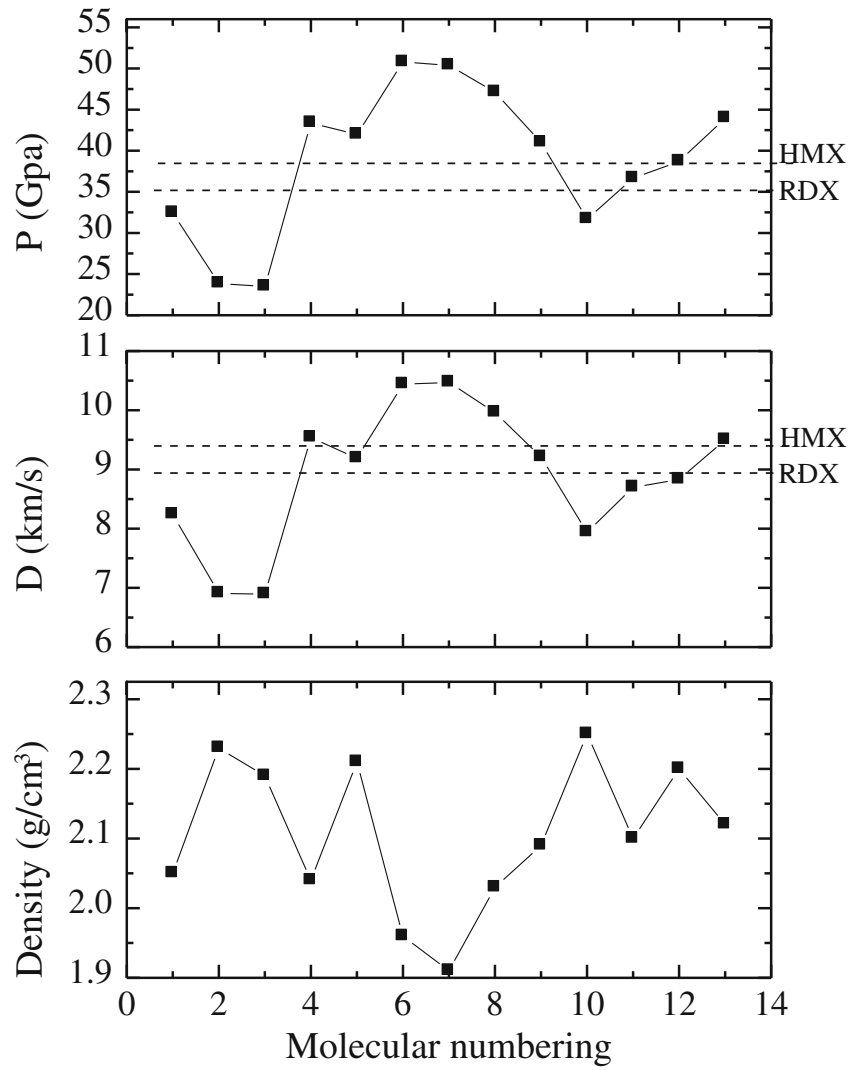

Figure 3. Detonation properties of the title compounds. weakest bond is usually used to indicate the relative sensitivity. Stronger the weakest bond, the more stable the energetic materials. The stability of the energetic material can be evaluated via BDE. Wiberg bond indexes (WBIs) from natural bond orbital (NBO) analysis were used to ascertain the weakest bond because of the presence of the same kind of bond in a molecule. A high WBI value represents a stronger bond and a low WBI value shows a weaker bond, so the bond with the smallest WBI among all bonds of the same type was considered. As it is not easy for the ring cleavage to take place in the thermal decomposition, table 5 lists some WBIs of the title compounds, not including furazan, tetrazole ring.

From table 5, WBIs of S-F bond in the title compounds are the smallest. For compounds (1)-(3), (8) and (13), WBIs of $S_{1}-F_{4}$ or $S_{1}-F_{5}$ bond are smaller than the WBIs of the other bonds, which indicates that the trigger linkage of these compounds appears to be $S_{1}-F_{4}$ or $\mathrm{S}_{1}-\mathrm{F}_{5}$ homolysis, while other bonds are relatively strong and resistant to rupture. For compounds (5)-(7) and (9)-(12), S1-F5 bond has the smallest WBIs and may be the trigger linkage. $\mathrm{S}_{1}-\mathrm{F}_{4}$ bond may be the trigger linkage for compound (4). Through the above analysis, S-F bond is the trigger bond for the thermolysis process in all the title compounds. Different substituent group slightly affects the WBI of the trigger linkage.

The BDEs of the weakest bonds for the title compounds are listed in table 6 . The calculated BDE can be used to measure the relative order of thermal stability for energetic materials. ${ }^{22}$

From table 6, it is noted that BDEs of the weakest bonds for the title compounds range from 351.1 to $388.3 \mathrm{~kJ} / \mathrm{mol}$, which are all lower than those of RDX and HMX. This shows that the title compounds have lower thermal stability and the substituted groups have no drastic effect on the BDEs of the weakest bonds. For compounds (1)-(3), the $\mathrm{S}_{1}-\mathrm{F}_{4}$ BDE gradually increases with the augmentation of field effects of the substituted groups, which is consistent with the conclusion obtained from the analysis of HOF. The BDE of the weakest bond for compound (4) is $383.0 \mathrm{~kJ} / \mathrm{mol}$, it is noted that the BDE of the weakest bond decreases when a $-\mathrm{CH}_{2}$ group is replaced by a $-\mathrm{NH}$ group. Similar analysis can be made for compounds (12) and (13).

Impact sensitivity of an energetic material is the degree to which it can be prompted to explode by external stimuli. It is also used as a measure of its safety, and a property that significantly influences the process used to produce the material, as well as applications of the material. Sitzmann et al. ${ }^{41}$ measured the tris(2-fluoro-2,2-dinitroethyl)-pentafluorothioethyl 


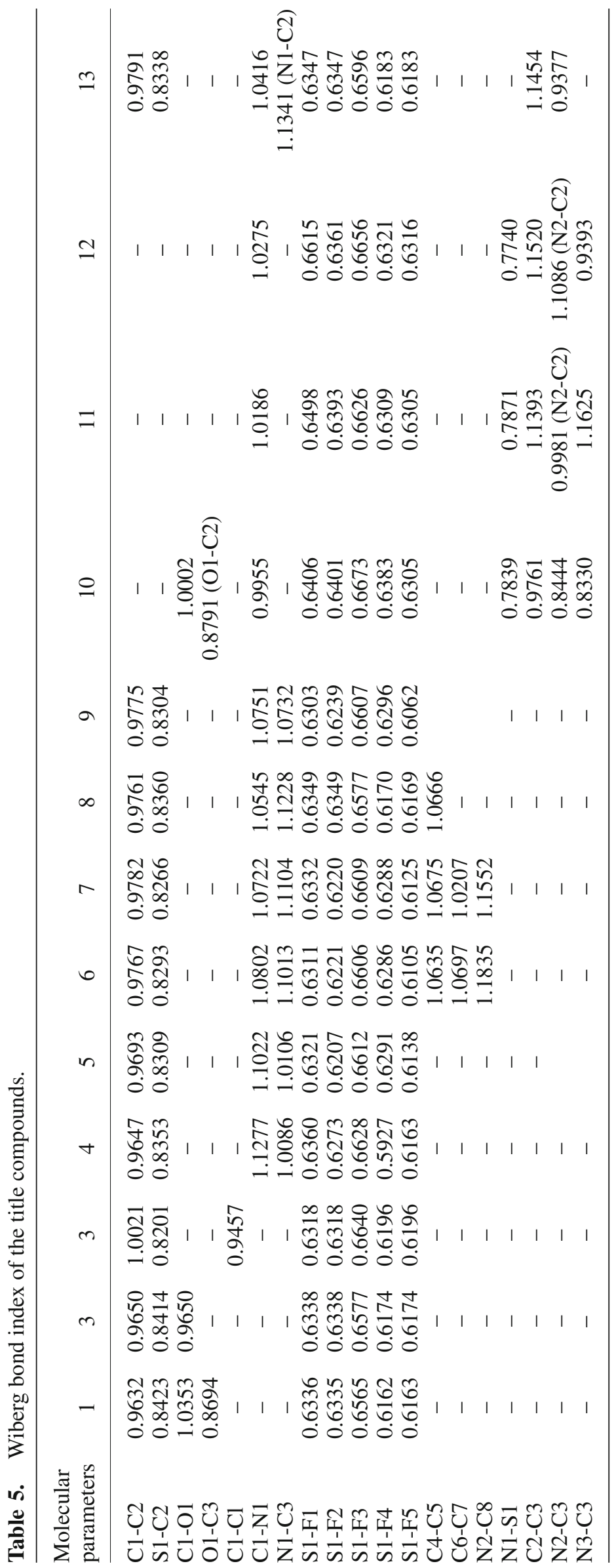


Table 6. Calculated BDEs $(\mathrm{kJ} / \mathrm{mol})$ of the weakest bonds for the title compounds at B3LYP/6-31G** level.

\begin{tabular}{llll}
\hline Compound & $\mathrm{S}_{1}-\mathrm{F}_{4}$ & $\mathrm{~S}_{1}-\mathrm{F}_{5}$ & $\mathrm{BDE}$ \\
\hline $\mathbf{1}$ & 0.6162 & & 381.5 \\
$\mathbf{2}$ & 0.6174 & & 383.0 \\
$\mathbf{3}$ & 0.6196 & & 388.3 \\
$\mathbf{4}$ & 0.5927 & & 383.0 \\
$\mathbf{5}$ & & 0.6138 & 383.3 \\
$\mathbf{6}$ & & 0.6105 & 379.1 \\
$\mathbf{7}$ & & 0.6125 & 378.1 \\
$\mathbf{8}$ & & 0.6169 & 373.1 \\
$\mathbf{9}$ & & 0.6062 & 381.3 \\
$\mathbf{1 0}$ & & 0.6305 & 360.0 \\
$\mathbf{1 1}$ & & 0.6305 & 351.1 \\
$\mathbf{1 2}$ & & 0.6316 & 358.2 \\
$\mathbf{1 3}$ & & & 372.6 \\
RDX & 0.6183 & & $694.7^{\mathrm{a}}$ \\
HMX & & & $747.3^{\mathrm{a}}$ \\
\hline
\end{tabular}

${ }^{\text {a Data from Ref. }}{ }^{40}$.

orthocarbonate and tris(2-fluoro-2.2-dinitroethyl)(2nitroethyl)orthocarbonate. They found that impact sensitivity of tris(2-fluoro-2,2-dinitroethyl)-pentafluorothioethyl orthocarbonate is larger than that of tris(2fluoro-2.2-dinitroethyl)(2-nitroethyl)orthocarbonate. This shows that the substituent of $\mathrm{SF}_{5}$ group makes the compounds more insensitive and possess good thermal stability. Thus, compounds with $\mathrm{SF}_{5}$ groups showed better thermal stability when compared with the corresponding compounds with nitro groups.

\section{Conclusions}

In this study, we have studied HOFs, thermal stability and detonation properties for a series of energetic materials containing $\mathrm{SF}_{5}$ group by using DFT-B3LYP method. Results show that it is a useful method to increase HOF values of energetic compounds by incorporating furazan or furoxan ring into them. Calculated detonation properties reveal that introduction of furazan ring or furoxan ring or tetrazole ring drastically enhances their detonation properties. An analysis of the BDEs for the weakest bonds indicates that S-F bond is the trigger bond for the thermolysis process in all the title compounds and the BDE of the weakest bond ranges from 351.1 to $388.3 \mathrm{~kJ} / \mathrm{mol}$. Considering the detonation performance and thermal stability, compounds (4)-(9), and (13) may be considered as potential candidates for high energy density materials with higher performance.

\section{Acknowledgements}

We thank the National Natural Science Foundation of China (Grant U1304111), China Postdoctoral Science Foundation (No. 2013 M531361) and Jiangsu Planned Projects for Postdoctoral Research Funds (No. 1201015B) and their support to this study.

\section{References}

1. Majano G, Mintova S, Bein T and Klapotke T M 2006 Adv. Mater. 182240

2. Bose R, Klapotke T M, Mayer P and Verma V 2006 Propell. Explos. Pyrot. 31263

3. Xu X J, Xiao H M, Ju X H, Gong X D and Zhu W H 2006 J. Phys. Chem. A110 5929

4. Gutowski K E, Rogers R D and Dixon D A 2006 J. Phys. Chem. A110 11890

5. Chavez D E, Hiskey M A and Gilardi R D 2000 Angew. Chem. Int. Ed. 391791

6. Kerth J and Lobbecke S 2002 Propell. Explos. Pyrot. 27 111

7. Gasco A and Boulton A J 1981 In Advances in heterocyclic chemistry (New York: Academic Press) pp. 157

8. Ronald A 2004 In Advanced energetic materials (Washington DC: National Academies Press) pp. 89

9. Olofson R A and Michelman J S 1965 J. Organ. Chem. 301854

10. Agrawal J P and Hodgson R 2007 In Organic Chemistry of explosives, (West Sussex: John Wiley \& Sons) pp. 245

11. Dolbier W R and Zheng Z 2011 J. Fluorine Chem. 132 389

12. Ye C, Gard G L, Winter R W, Syvret R G, Twamley B and Shreeve J M 2007 Org. Lett. 93841

13. Gao H, Ye C, Winter R W, Gard G L, Sitzmann M E and Shreeve J M 2006 Eur. J. Inorg. Chem. 163221

14. Frisch M J, Trucks G W, Schlegel H B, Scuseria G E, Robb M A, Cheeseman J R, Zakrzewski V G, Montgomery J A, Stratmann R E, Burant J C, Dapprich S, Millam J M, Daniels A D, Kudin K N, Strain M C, Farkas O, Tomasi J, Barone V, Cossi M, Cammi R, Mennucci B, Pomelli C, Adamo C, Clifford S, Ochterski J, Petersson G A, Ayala P Y, Cui Q, Morokuma K, Malick D K, Rabuck A D, Raghavachari K, Foresman J B, Cioslowski J, Ortiz J V, Baboul A G, Stefanov B B, Liu G, Liashenko A, Piskorz P, Komaromi I, Gomperts R, Martin R L, Fox D J, Keith T, Al- Laham M A, Peng C Y, Nanayakkara A, Gonzalez C, Challacombe M, Gill P M W, Johnson B, Chen W, Wong M W, Andres J L, Gonzalez C, Head G M, Replogle E S and Pople J A 2003 GAUSSIAN 03, Revision B.02 (Pittsburgh PA: Gaussian Inc.)

15. Zeng Q and Li Z C 2011 J. Phys. Org. Chem. 24 1058

16. Chen P C, Chieh Y C and Tzeng S C 2003 J. Mol. Struct. (Theochem.) 634215

17. Li X H, Zhang R Z and Zhang X Z 2010 J. Hazard. Mater. 183622 
18. Kamlet M J and Jacobs S J 1968 J. Chem. Phys. 4823

19. Zhang X H and Yun Z H 1989 Explosive chemistry (Beijing: National Defense Industry Press)

20. Politzer P, Martinez J, Murray J S, Concha M C and Toro-Labbé A 2009 Mol. Phys. 1072095

21. Hehre W J, Radom L and Schleyer P V R 1986 Ab initio molecular orbital theory (New York: Wiley)

22. Rice B M, Sahu S and Owens F J 2002 J. Mol. Struct. (Theochem.) $\mathbf{5 8 3} 69$

23. NIST Standard Reference Data Base Number 69 (http:// webbook.nist.gov/chemistry)

24. Frenkel M, Kabo G J, Marsh K N, Roganov G N and Wilhoit R C 1994 Thermodynamics of organic compounds in the gas state (College Station TX: Thermodynamic Research Center) pp. 124

25. Cox J O and Pilcher G 1970 Thermochemistry of organic and organometallic compounds (New York: Academic Press) pp. 218

26. Zheng Z Q, Wu T H, Mao F L, Zhang Q N and Chen F 2005 Chem. Eng. Oil Gas 3487

27. Balepin A A, Lebedev V P, Miroshnichenko E A, Koldobskii G I, Ostovskii V A, Larionov B P, Gidaspov B V and Lebedev Yu A 1977 Svoistva Veshchestv Str. Mol. 293

28. Wei T, Zhang J J, Zhu W H, Zhang X W and Xiao H M 2010 J. Mol. Struct. (Theochem) 95655
29. Selmi M and Tomasi J 1995 J. Phys. Chem. 995894

30. Talawar M B, Sivabalan R, Mukundan T, Muthurajan H, Sikder A K, Gandhe B R and Rao A S 2009 J. Hazard. Mater. 161589

31. Gilardi R, Flippen-Anderson J L and Evans R 2002 Acta Crystallogr. $\mathbf{5 8} 972$

32. Willer R L 1993 Propell. Explos. Pyrotech. 865

33. Cao C Z 2003 Substituent effects in organic chemistry (Beijing: Science Press) pp. 249

34. Atkins PW 1982 Physical chemistry (Oxford: Oxford University Press) pp.189

35. Politzer P, Lane P and Murray J S 2011 Cent. Eur. J. Energ. Mater. 839

36. Politzer P and Murray J S 2011 Cent. Eur. J. Energ. Mater. 8209

37. Byrd E F C and Rice B M 2006 J. Phys. Chem. A110 1005

38. Lu T 2012 Multiwfn Revision 2.5.2 (Beijing: Beijing Science and Technology).

39. Sasada Y 1984 Molecular and crystal structures in chemistry handbook (Tokyo: The Chemical Society of Japan) pp. 157

40. Zhang J J, Gao H W, Tao W and Wang C J 2010 Acta Phys. Chim. Sin. 263337

41. Sitzmann M E, Gilligan W H, Ornellas D L and Thrasher J S 1990 J. Energ. Mater. 4352 